\title{
Conf-940483--1
}

UCRL-JC-115950

PREPRINT

\section{Dual-Band Infrared Imaging to Detect Corrosion Damage Within Airframes and Concrete Structures}

\author{
N. K. Del Grande and P. F. Durbin
}

This paper was prepared for submittal to the Proceedings of SPIE Thermosense XVI, International Conference on Thermal Sensing and

Imaging and Diagnostic Applications

Orlando, Florida

April 4-8, 1994

January 1994

- This is a preprint of a paper intended for publication in a journal or proceed ings. Since changes may be made before publication, this preprint is made available with the understanding that it will not be cited or reproduced without the permission of the author. 


\section{DISCLAIMIER}

This document was prepared as an account of work sponsored by an agency of the U'nited States Government. Neither the L'nited States Government nor the University of California nor any of their employees, makes any warranty, express or implied, or assumes any legal liability or responsibility for the accuracy, completeness, or usefulness of any information, apparatus, product, or process disclosed. or represents that its use would not infringe privately owned rights. Reference herein to any specific commercial products, process, or service by trade name. trademark, manufacturer, or otherwise, does not necessarily constitute or imply its endorsement, recommendation, or favoring by the l'nited States Government or the Liniversity of California. The views and opinions of authors expressed herein do not necessarily state or reflect those of the L'nited States Government thereof, and shall not be used for advertising or product endorsement purposes. 
 \\ Dual-band infrared imaging to detect corrosion damage within airframes and concrete structures $\mathrm{O} /$ \\ N. K. Del Grande and P. F. Durbin \\ Lawrence Livermore National Laboratory \\ P. O. Box 808, Livermore CA 94550
}

\begin{abstract}
We are developing dual-band infrared (DBIR) imaging and detection techniques to inspect airframes and concrete bridge decks for hidden corrosion damage. Using selective DBIR image ratios, we enhanced surface temperature contrast and removed surface emissivity noise associated with clutter. Our surface temperature maps depicted defect sites, which heat and cool at different rates than their surroundings. Our emissivity-ratio maps tagged and removed the masking effects of surface clutter. For airframe inspections, we used time-resolved DBIR temperature, emissivity-ratio and composite thermal inertia maps to locate corrosion-thinning effects within a flash-heated Boeing 737 airframe. Emissivity-ratio maps tagged and removed clutter sites from uneven paint, dirt and surface markers. Temperature and thermal inertia maps characterized defect sites, types, sizes, thicknesses, thermal properties and material-loss effects from airframe corrosion. For concrete inspections, we mapped DBIR temperature and emissivity-ratio patterns to better interpret surrogate delamination sites within naturallyheated, concrete slabs and removed the clutter mask from sand pile-up, grease stains, rocks and other surface objects.
\end{abstract}

\subsection{INTRODUCTION}

This paper investigates recent advances in thermography for nondestructive inspections (NDI) of aluminum airframes and concrete bridge decks. Infrared imaging has the potential of rapidly inspecting large areas at video frame rates ( 30 frames per second) to provide an early warning of subsurface defects (e.g., corrosion thinning and by-products, voids, disbonds, cracks and delaminations). Using single-band infrared (SBIR) imaging methods, scientists have successfully depicted the sites of subsurface defects in manmade structures [1-6]. However, SBIR methods impede detection of weak heat flow anomalies from hidden corrosion, since emissivity-noise from clutter is often larger than temperature signals from hidden defects.

We used a stimulated, emissivity-corrected, dual-band infrared (DBIR) method to image weak heat flows which occur in association with subsurface defects in manmade structures. Typically, the DBIR method provides from five to ten times improved signal-to-noise, and better interpretability, compared to SBIR methods. Previous DBIR applications have depicted:

- Geothermal aquifers under 6 to 60 meters of dry soil $[7,8]$,

- Cemetery walls, trenches and a building foundation under $80 \mathrm{~cm}$ of asphalt and debris [9],

- Buried mines, rocks and objects under 1 to $20 \mathrm{~cm}$ of disturbed sand, soil, or sod [9-15],

- Airframe corrosion within a lap splice under $1 \mathrm{~mm}$ or $2 \mathrm{~mm}$ of exposed aluminum skin [15-18].

\subsection{DUAL-BAND INFRARED (DBIR) THERMAL IMAGING BACKGROUND}

Using the patented passive DBIR thermal imaging method [19], we imaged two simultaneously recorded infrared wavelength bands at 3-5 $\mu \mathrm{m}$ and 8-12 $\mu \mathrm{m}$. We exploited a property of Planck's Radiation law, that at $288 \mathrm{~K}\left(15^{\circ} \mathrm{C}\right)$, the DBIR radiant emittance signals varied as emissivity times absolute temperature $(T)$ to the power $(50 / \lambda)$ where $\lambda$ is the wavelength in $\mu \mathrm{m}$. This method provides the rationale to select DBIR image ratios, which decouple surface temperature-difference signals from spatially varying surface-emissivity noise [20]. The DBIR method clarifies thermal image interpretation by removing noise.

To obtain precise airborne temperature survey maps, we measure true (corrected) temperatures by applying four corrections to the image data. The first is a correction to adjust the radiometric (brightness) data at the two wavelengths for the ambient background. The second correction applies the power law relationship between signal intensities and surface temperatures. The third correction accounts for air-path absorption of the DBIR signals, while the fourth correction takes into account reflected sky radiation backgrounds $[7,8]$.

We mapped apparent temperatures near $5 \mu \mathrm{m}$ and $10 \mu \mathrm{m}$, enhanced temperatures (proportional to $\mathrm{T}^{5}$ ) and the emissivity-ratio (E-ratio): $\left(\mathrm{E}_{10}\right)^{2} / \mathrm{E}_{5}$ for solar-heated and heat-stimulated targets. Temperature maps of solar-heated, underground targets have patterns of conducted heat generated at subsurface object sites which heat and cool at different rates than the sites of the surrounding materials [9-15]. Temperature maps of flash-heated metallic targets have shown hidden defects and corrosionrelated material-loss effects which can be used for nondestructive inspection of airframes as described below [15-18]. 


\subsection{STIMULATED DBIR IMAGING OF AIRFRAME CORROSION EFFECTS}

We flash-heated aircraft structures to locate hidden corrosion pockets, disbonds (within lap joints) and other subsurface defects [15-18]. We used DBIR image ratios from DBIR cameras which scan infrared at 3-5 $\mu \mathrm{m}$ and 8-12 $\mu \mathrm{m}$ to enhance surface temperature contrast and remove the mask of surface emissivity clutter from dirt, dents, tape, markings, ink, sealants, uneven paint, paint stripper, exposed metal and roughness variations. This clarified interpretation of subtle heat flow anomalies associated with hidden defects and corrosion-related, material-loss effects..

We computed DBIR image ratios of enhanced temperature contrast (T5) and emissivity-ratio (E-ratio) maps, based on an expansion of Planck's radiation law [20]:

$$
\begin{gathered}
\left(\mathrm{T} / \mathbf{T}_{\mathrm{av}}\right)^{5}=\left(\mathrm{S} / \mathbf{S}_{\mathrm{av}}\right) /\left(\mathrm{L} / \mathbf{L}_{\mathrm{av}}\right) \\
\text { E-ratio }=\left(\mathbf{L} / \mathbf{L}_{\mathrm{av}}\right)^{\mathbf{2}} /\left(\mathbf{S} / \mathbf{S}_{\mathrm{av}}\right)
\end{gathered}
$$

where $S$ is the short-wavelength, $3.5 \mu \mathrm{m}$, intensity (e.g., I5),$S_{\mathrm{av}}$ is the average value of the pixels in $S, L$ is the long wavelength, 8-12 $\mu \mathrm{m}$, intensity (e.g., $I_{10}$ ) and $L_{a v}$ is the average value of the pixels in $L$.

The Boeing 737 airframe DBIR image and image-ratio maps (see Figure 1) show sites with above-ambient temperatures and emissivity-ratios. These maps allow us to distinguish corrosion-related thickness loss effects from emissivity clutter (e.g., from dirt, tape markers, uneven paint, exposed metal and roughness variations on the Boeing 737 fuselage skin).

Corrosion-related thickness-loss effects are best measured at 0.4 seconds after the heat flash. Temperatures at $0.4 \mathrm{~s}$ are sensitive to material loss effects within a lap splice and insensitive to timing uncertainties. The timing is early enough to provide a good temperature contrast for sites with and without material loss effects from corrosion. At later times, trapped materials mask the temperature-time history which characterizes material-loss effects for corrosion sites. The temperature contrast seen in Figure 2 remains about the same from $0.4 \mathrm{~s}$ to $3.2 \mathrm{~s}$. Corrosion by-products trapped within the lap splice behave like an insulator, after $0.4 \mathrm{~s}$, impeding conduction of heat from the outer to the inner lap splice surface.

We established the correlation between percent thickness loss and above-ambient surface temperature rise, at 0.4 seconds after the heat flash, based on our measurements for five specimens which averaged a $24 \pm 5 \%$ thickness loss per ${ }^{\circ} \mathrm{C}$ temperature rise. These specimens included a F-18 partially corroded wing box (with a $2.9 \mathrm{~mm}$ uncorroded thickness) and four $1.0 \mathrm{~mm}$ to $3.9 \mathrm{~mm}$ thickness aluminum panels with milled, flat-bottom holes, where thickness losses were $6 \%$ to $62 \%$.

We mapped the airframe composite thermal inertia, $(\mathrm{k \rho c})^{1 / 2}$, where $\mathrm{k}$ is thermal conductivity, $\rho$ is density, and $\mathrm{c}$ is heat capacity. The composite thermal inertia, or effusivity, varies as the inverse slope of the surface temperature versus the inverse square root of time. Thermal inertia maps remove uneven heating effects. Thermal inertia mapping is not a new concept. It has been discussed in reference to other applications [21-24]. Airframe lap splices have relatively low thermal inertia at sites in Figure 3, where there are (10 \pm 3$)$ percent material-loss effects from corrosion thinning compared to other sites $[17,18]$.

Composite thermal inertia maps characterize shallow skin defects within the lap splice at early times ( 0.0 to $0.3 \mathrm{~s})$, shown in Figure 3(a), and deeper skin defects within the lap splice at late times (1.6 to $8.0 \mathrm{~s}$ ), shown in Figure 3 (b). The Boeing 737 composite thermal inertia map, at 1.6 to $8.0 \mathrm{~s}$, depicted a butterfly-like pattern at the site where corrosion entered the inside, at the backside of the lap splice, beneath the galley and the latrine. Expansion of corrosion by-products at this site produced bulges between the rivets, which is an effect known as "pillowing". The combination of pillowing with lower than ambient thermal inertia values at the same airframe lap splice site confirmed that corrosion thinning was the type of defect detected.

\subsection{CONCRETE IMAGING TEST PLAN}

We discuss the procedure for imaging subsurface defects in concrete and our initial results obtained from limited testing of (small) concrete test slabs. We used commercial DBIR cameras, a 12-bit digital image processing system, specialized algorithms and a tower platform to test the feasibility for imaging subsurface defects in concrete slabs such as are found on bridge decks. We conducted tests under varied environmental conditions (during day and night, for cloudy and clear days).

Four larger concrete test slabs were built (six feet on a side and 6 inches thick) to optimize procedures for mapping hidden delaminations in bridge deck structures. Delaminations can occur near corroded rebars from the expansion of corrosion byproducts. Some of the test slabs were covered with a 2 inch thick layer of asphalt. The slabs provided surrogate concrete bridge deck sections for the purpose of our feasibility study. We plan to conduct field tests from a tower platform to test the optics needed for bridge deck inspections where the IR imagers can be located 10 to 14 feet above the pavement. 


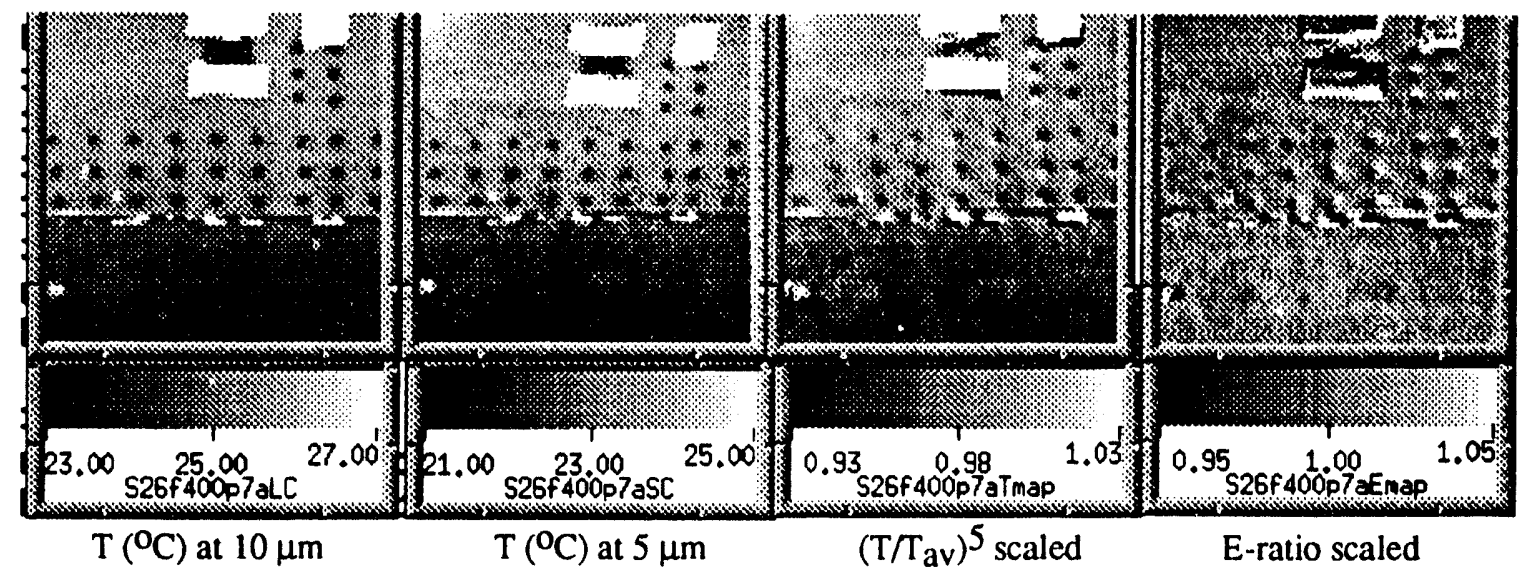

Figure 1. The Boeing 737 aircraft fuselage, Stringer 26 (s26f400.7) showing (from left to right) two apparent temperature 10 $\mu \mathrm{m}$ and $5 \mu \mathrm{m}$ maps, an enhanced contrast temperature map and an emissivity-ratio map. Note temperature and emissivityratio differences for various black cloth (white, hot) and metal (black, cold) tape markers at top, right of center and masking tape painted black (white, hot) at top right corner. Note non-uniform paint applied below lap splice at bottom [17 in color,18].

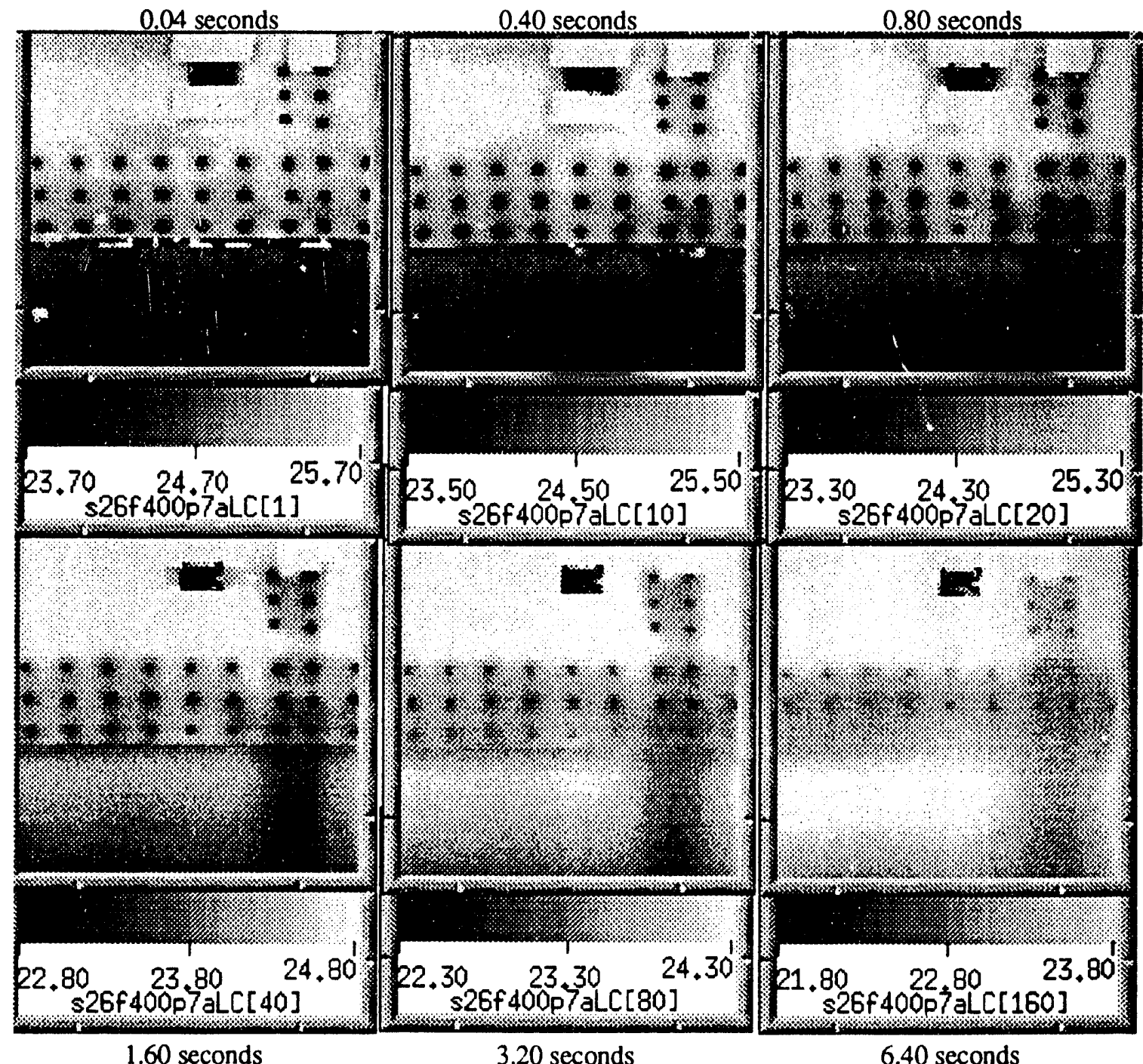

Figure 2. The $10 \mu \mathrm{m}$ dynamic temperature variations for the Boeing 737 lap splice images at different times after flash. 


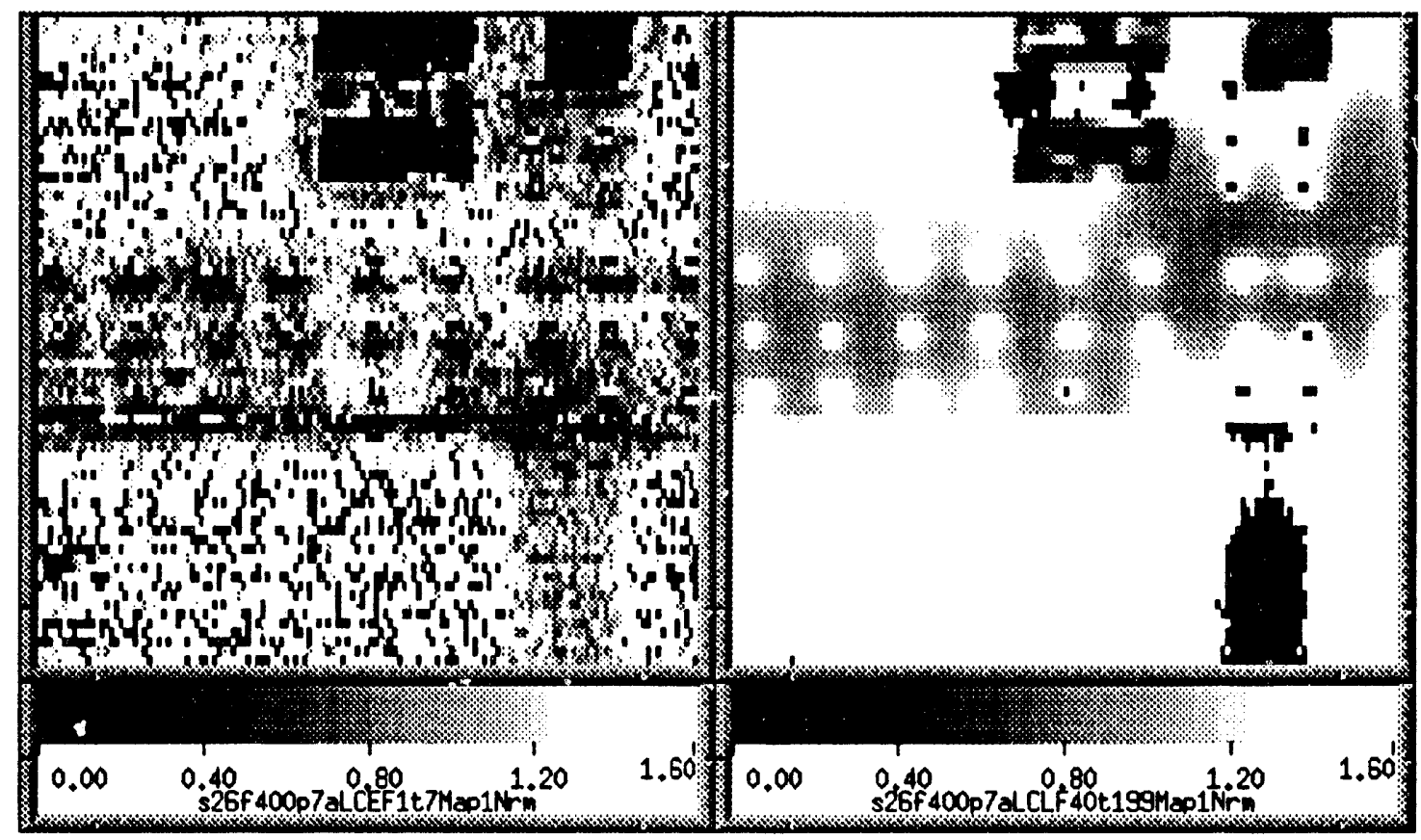

3 (a) Early time thermal inertia at $0.0 \mathrm{~s}$ to $0.3 \mathrm{~s}$.

3 (b) Late time thermal inertia at $1.6 \mathrm{~s}$ to $8.0 \mathrm{~s}$.

Figure 3. Composite thermal inertia maps of the Boeing 737 aircraft fuselage, Stringer 26 (s26f400.7). Note the dark "butterfly-like" site on the late-time thermal inertia map where corrosion entered the lap splice from inside the aircraft. This corrosion-damaged site was beneath the galley and the latrine. Also, note the relatively low thermal inertia values for frontsurface cloth and masking tape markers and back surface tear straps (bottom right corner). Colored version in refererce [17].

We used our tests to optimize the DBIR system response to thermal signature differences between normal and defective concrete bridge decks and to clarify interpretation of subsurface cracks, voids and delaminations masked by surface roughness variations, staining, sand, dirt, metal objects, gravel or moisture. We are developing algorithms for image data fusion, clutter rejection and feature extraction, using thermal models to better understand the concrete heat transfer properties.

\subsection{INITIAL CONCRETE IMAGING EXPERIMENT}

Two small ( 2 feet square ) concrete design test slabs were cast to help select the most appropriate delamination materials and evaluate techniques for embedding thermal measuring sensors. Each small slab is $51 / 2$ inches thick and contains one layer of \#4 rebar in the form of a 16 inch square with a center cross, forming 4 to 8 inch grids and located 2 inches below the surface. See Figure 4.

Slab I contained a surrogate delamination site produced by a rectangular layer of Aerogel ( $1 / 2$ inch thick, 1.25 inch below the surface, 2.25 inch length by 4 inch width) at the top right comer of Slab I in the diagram of Figure 4 and the thermal images of Figure 5. This slab also had a 5/8 inch diameter hole through the slab parallel to the surface in place of one center rebar and a $1 / 8$ thick by 6 inch long foam strip wrapped around a portion of rebar to simulate corrosion products.

Slab II contained two styrofoam inserts, four inches square, located 2 inches below and parallel to the surface as shown in the diagram of Figure 4 and depicted by the thermal images shown in Figure 6 . One is $1 / 8$ inch thick and one is $1 / 4$ inch thick. This slab also has one thermistor (temperature) sensor located 2 inches below the surface.

A third (existing) concrete block, 2 inches thick, with a 6 inch width by 9 inch length, was used for surface clutter tests. The objects on the concrete slab surface are shown in Figure 4. Their thermal images are depicted in Figure 7. The block has a motor oil stain over $1 / 3$ of its area, two rocks and two metal objects, $3 / 4$ inch in size, placed in different locations.

All three slabs were imaged using an Agema 880 dual band infrared scanner. The two newly cast slabs, located outside and exposed to solar heating, were imaged 24 hours after the concrete was poured. The first scans were done at 7:30 AM and no definite images of the delaminations were seen. At $11 \mathrm{AM}$, the solar gain was sufficient to show the delamination thermal patterns on the surface temperature image. The temperature at a 2 inch depth was $10.4{ }^{\circ} \mathrm{C}$ at $7: 08 \mathrm{AM}$ and $21.0^{\circ} \mathrm{C}$ at $11: 32$ AM. Further testing will be an aid for planning times and conditions to optimize bridge deck inspections. 


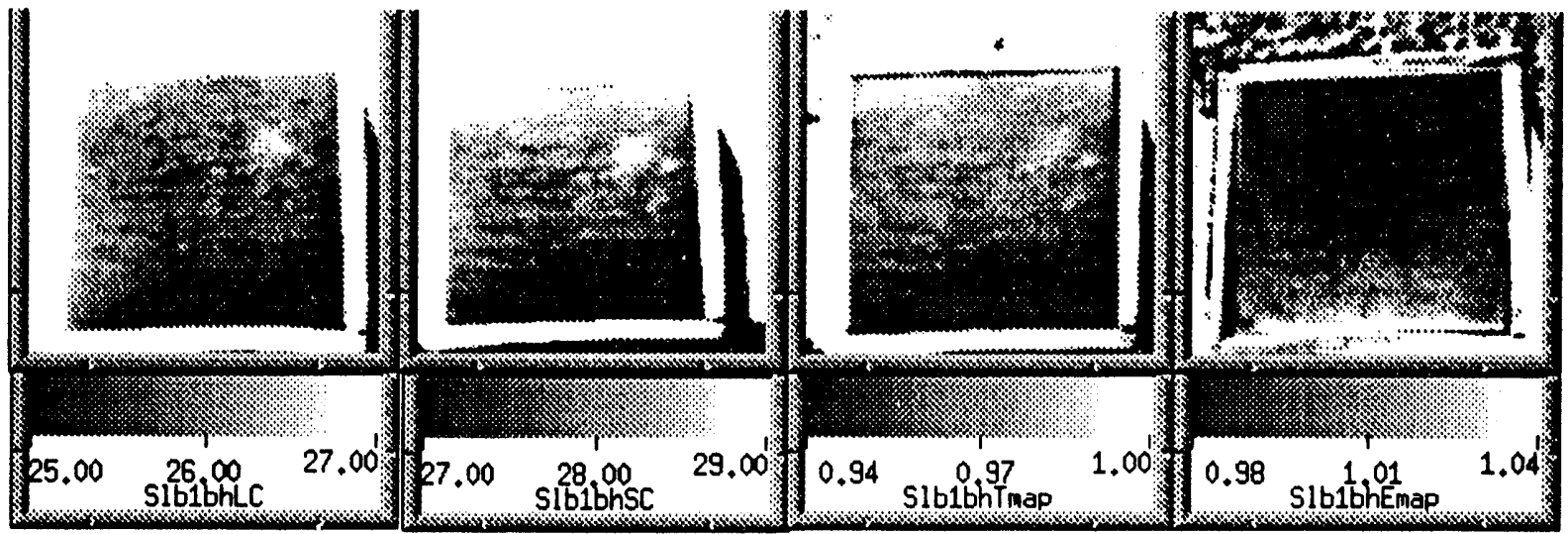
(a) $\mathrm{T}\left({ }^{\circ} \mathrm{C}\right)$ at $10 \mu \mathrm{m}$
(b) $\mathrm{T}\left({ }^{\circ} \mathrm{C}\right)$ at $5 \mu \mathrm{m}$
(c) $\mathrm{T}^{5}$ (relative scale)
(d) Emissivity-Ratio

Figure 5. Left to right, maps of Slab I $10 \mu \mathrm{m}$ (a), $5 \mu \mathrm{m}$ (b) and enhanced (c) temperatures and emissivity-ratios (d).

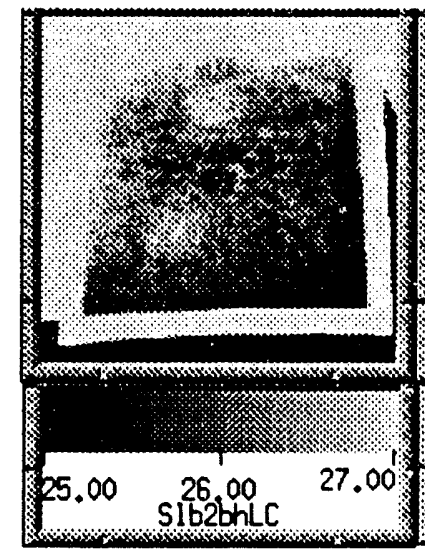

(a) $\mathrm{T}\left({ }^{\circ} \mathrm{C}\right)$ at $10 \mu \mathrm{m}$

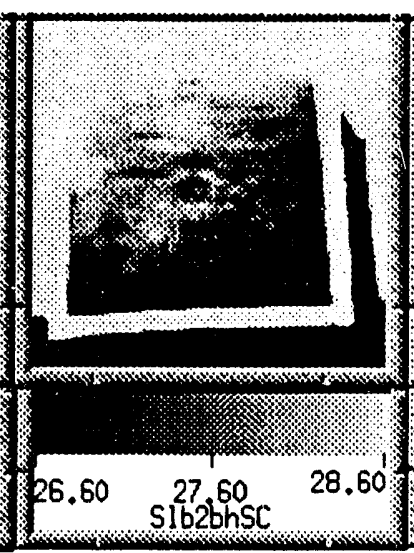

(b) $\mathrm{T}\left({ }^{\circ} \mathrm{C}\right)$ at $5 \mu \mathrm{m}$

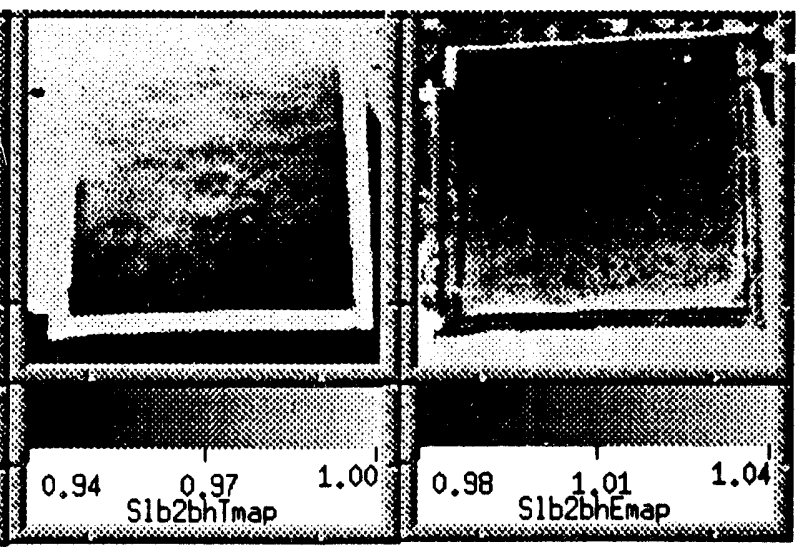

(c) $\mathrm{T}^{5}$ (relative scale)

(d) Emissivity-Ratio

Figure 6. Left to right, maps of Slab II $10 \mu \mathrm{m}$ (a), $5 \mu \mathrm{m}$ (b) and enhanced (c) temperatures and emissivity-ratios (d).

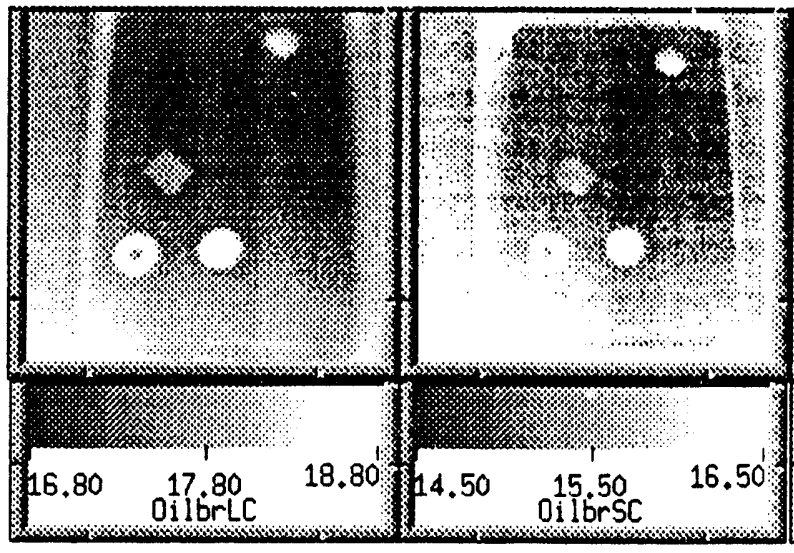

$\begin{array}{ll}\text { (a) } \mathrm{T}\left({ }^{\circ} \mathrm{C}\right) \text { at } 10 \mu \mathrm{m} & \text { (b) } \mathrm{T}\left({ }^{\circ} \mathrm{C}\right) \text { at } 5 \mu \mathrm{m}\end{array}$

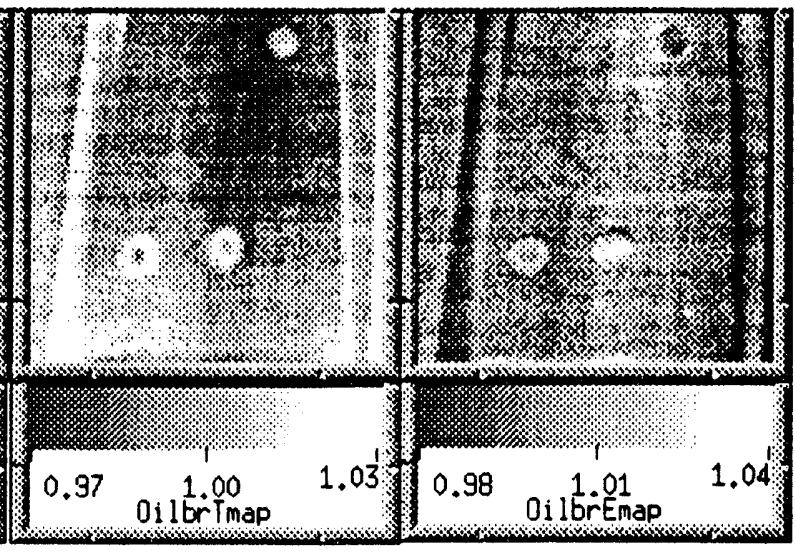

(c) $\mathrm{T}^{5}$ (relative scale)

(d) Emissivity-Ratio

Figure 7. Left to right, maps of concrete block $10 \mu \mathrm{m}$ (a), $5 \mu \mathrm{m}$ (b) and enhanced (c) temperatures and emissivity-ratios (d). 


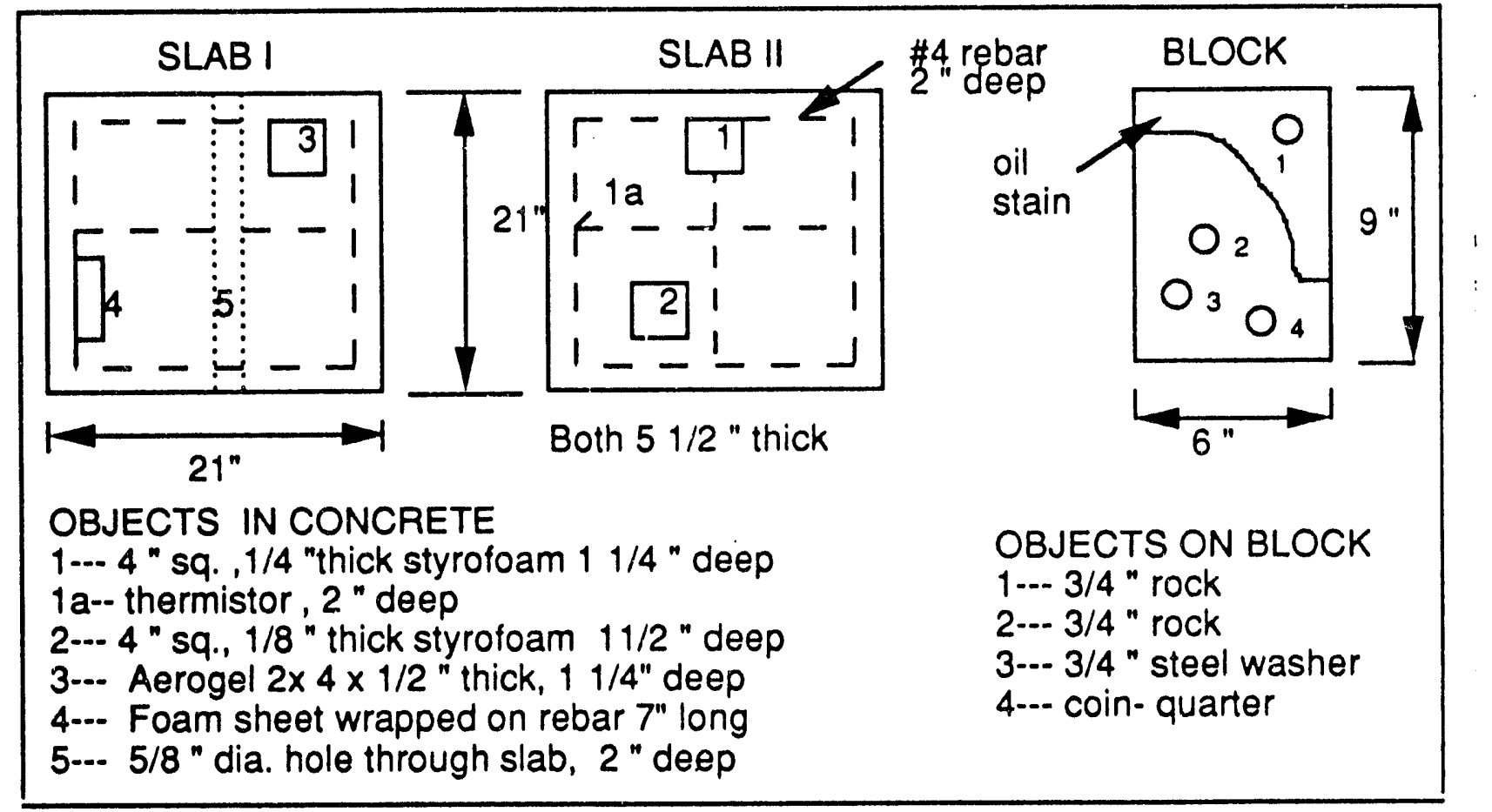

Figure 4. Diagrams: Objects in Slab I (Fig. 5), Slab II (Fig. 6) and on concrete block (Fig. 7).

\subsection{RESULTS AND CONCLUSIONS}

DBIR ratios of co-registered 3-5 and 8-12 $\mu \mathrm{m}$ images provide separate temperature and emissivity-ratio maps to improve the defect site signal-to-noise and clarify interpretation of airframe corrosion damage. We established the relationship between a $1{ }^{\circ} \mathrm{C}$ temperature rise $(0.4 \mathrm{~s}$ after the heat flash) and a $24 \pm 5 \%$, corrosion-related, thickness loss. The emissivity-ratio map enabled us to tag (and remove) the surface clutter sites which have spatially varying surface emissivity differences.

Clutter may result from a variety of surface features (e.g., roughness variations, dirt, dents, uneven paint, sealants, stripper materials, cleaner residues, metal markers, tape and ink). The use of emissivity-ratio maps to identify (then remove) clutter sites on co-registered temperature maps is unique at LLNL. Emissivity-ratio maps significantly improve the signal-to-noise (S/N) for siting corrosion damage, by a factor of five or ten, compared to the S/N achievable with SBIR methods. By tagging (and removing) the mask from surface clutter, we clarify interpretation of corrosion damage.

Aircraft skin thickness-loss from corrosion has been measured using dual-band infrared (DBIR) imaging on a flash-heated Boeing 737 fuselage structure. Our procedure mapped surface temperature differences at sites without surface-emissivity clutter. We mapped the lap splice composite thermal inertia, $(\mathrm{kpc})^{1 / 2}$, which characterizes shallow skin defects within the lap splice at early times $(<0.3 \mathrm{~s})$ and deeper skin defects within the lap splice at late times $(>1.6 \mathrm{~s})$. Corrosion thinning and byproducts invaded the inside of the Boeing 737 airframe lap splice, beneath the galley and the latrine, where we observed "pillowing" from volume build-up of corrosion by-products.

The initial testing of small concrete test slabs depicted surrogate delamination sites with varying contrast at different times. The larger concrete structures will be cured, aged and tested under various weather conditions. We will optimize the surface temperature contrast associated with subsurface delamination sites and remove the effects of typical surface clutter. Based on the results of our investigations, we expect to improve our capability to inspect actual concrete bridge deck structures under the most appropriate diurnal and seasonal conditions.

At approximately 11:00 a.m., both concrete test slabs had (surrogate) delamination sites which were warmer than their surroundings. The Slab I defect site averaged about $0.9^{\circ} \mathrm{C}$ warmer, the Slab II upper defect site about $2.2^{\circ} \mathrm{C}$ warmer and the Slab II lower defect site about $1.4^{\circ} \mathrm{C}$ warmer than their respective surroundings. The statistical temperature variations for the concrete test slabs were about $0.2^{\circ} \mathrm{C}$ at $8-12 \mu \mathrm{m}$ and $0.3^{\circ} \mathrm{C}$ at $3-5 \mu \mathrm{m}$. Clutter from sand pile-up produced cool sites at the center of the Slab II temperature maps. The emissivity variations were quite small for concrete with very little surface clutter. 
We note that metal objects on the bottom rows of the apparent temperature, enhanced temperature and emissivity-ratio maps of objects on the concrete block, see Figure 6, were both warmer than the rocks and had higher emissivity-ratio values which contrasted more with the concrete than the rocks. Also, we note that clutter sites from surface objects on the concrete block had sharp edges, whereas surface temperature patterns of defect sites from surrogate delaminations within concrete slabs had edges which were less well defined. We expect these features to help distinguish corrosion-related delamination sites from surface clutter sites to clarify interpretation of concrete bridge deck inspections.

\subsection{ACKNOWLEDGMENTS}

This work was performed under the auspices of the U.S. Department of Energy by the Lawrence Livermore National Laboratory under contract number W-7405-ENG-48 for the FHWA order number DTFH61-93-Y-00145 and Interagency Agreement DTFA03-92-A-00007 for the FAA Aging Aircraft Non-Destructive Inspection R\&D Program. We thank Steven Chase (FHWA) for valuable technical discussions, and Chris Seher, P. K. Bhagat and David Galella at the FAA Technical Center for their helpful suggestions. We are grateful for the support efforts of Gary Phipps, Craig Jones, Don Harmon and Pat Walter at Sandia National Laboratory, Albuquerque, NM where we inspected the Boeing 737 aircraft owned by the FAA/AANC (Aging Aircraft Nondestructive Inspection Center). We thank M. Lawrence and N. Nguyen for calibrated thermistor measurements, M. Gorvad for image processing, L. Hrubisch for the Aerogel samples, M. Finger, David Fields and Michael Carter for use of the Agema DBIR system, Ken Dolan, FAA Project Leader, for helpful suggestions and Satish Kulkarni, NDE Section Leader, for his support.

\subsection{REFERENCES}

1. Spicer, J. W. M., W. D. Kerns, L. C. Aamodt, R. Osiander and J. C. Murphy, "Time-Resolved Infrared Radiometry (TRIR) using a Focalplane Array for Characterizations of Hidden Corrosion", Proceedings of SPIE Conference 1933: Thermosense XV Ed. Lee R. Allen, Orlando FL p. 148 (1993).

2. Favro, L. D., P. K. Kuo, R. L. Thomas, T. Ahmed and Y. X. Wang, "Thermal wave imaging of corrosion and disbonds in aircraft structures" in Proceedings of SPIE Conference 2001: Nondestructive Inspection of Aging Aircraft. Ed. Michael T. Valley, Nancy K. Del Grande and Albert S. Kobayashi, San Diego CA (1993).

3. Selman, John J. and J. Ted Miller, "Evaluation of a prototype thermal wave imaging system for nondestructive evaluation of composite and aluminum aerospace structures", Proceedings of SPIE Conference 1933: Thermosense XV Ed. Lee R. Allen, Orlando FL p. 178 (1993).

4. Syed, Hazari I., and K. Elliott Cramer, "Corrosion Detection in Aircraft Skin", Proceedings of SPIE Conference 1933: Thermosense XV Ed. Lee R. Allen, Orlando FL p. 160 (1993).

5. Joyce, Richard P., "Rapid Non-Destructive Delamination Detection" in Federal Highway Administration Report No. FHViA/RD-85,051. Final Report.pp. $42-57$ and Appendix B (1985).

6. Vavilov, V. P. and X. Maldague, "Dynamic thermal tomography: a new promise in the IR thermography of solids", Proceedings of SPIE Conference 1682; Thermosense X1V Ed. Jan K. Eklund, Orlando FL p. 194 (1992).

7. Del Grande, N., "Airborne and Field Temperature Surveys Compared At Long Valley KGRA, California", Geothermal Resources Council Transactions 5 . 71 (1978).

8. Del Grande, N. K., "Airborne Temperature Survey Maps of Heat Flow Anomalies for Exploration Geology", Proceeding of International Symposium on Remote Sensing of Environment. Second Thematic Conference on Remote Sensing for Exploration Geology Dec. 1982. Reprinted in Geothermal Resources Council Bulletin 14, p.3 (1985).

9. Del Grande, N. K., G. A. Clark, P. F. Durbin, D. J. Fields, J. E. Hernandez and R. J. Sherwood, "Buried Object Remote Detection For Law Enforcement", Surveillance Technologies, SPIE Vol. 1479, 335 (1991).

10. Del Grande, N. K., "Temperature Evaluated Mine Position Survey (TEMPS) Application of Dual Band Infrared Methodology", Proceedings of the 1990 Meeting of the IRIS Specialty Group on Passive Sensors, IRIA/ERIM sponisored symposium (1990). 
11. Del Grande, N. K., "Sensor Fusion Methodology for Remote Detection of Buried Land Mines", Proceedings of the 3rd National Symposium on Sensor Fusion, Orlando, Fl, Vol. 1, IIAC/ERIM, p.407, (1990).

12. Del Grande, N., "Airborne Detection Of Buried Minefields", Energy and Technology Review. University of California LLNL Report, UCRL-52-000-91-12, 9 (1991).

13. Del Grande, N. K., P. F. Durbin, M. R. Gorvad, D. E. Perkins, G. A. Clark, J. E. Hernandez and R. J. Sherwood, "Dualband Infrared Capabilities for Imaging Buried Object Sites" in Proceedings of SPIE Conference 1942: Underground and Obscured Object Imaging and Detection, Ed. N. Del Grande, I. Cindrich and P. Johnson, Orlando FL (1993).

14. Clark, G. A., J. E. Hemandez, S. K. Sengupta, R. J. Sherwood, P. C. Schaich, M. R. Buhl, R. J. Kane, M. J. Barth, N. K. Del Grande, "Sensor Feature Fusion for Detecting Buried Objects" Proceedings of SPIE Conference 1942: Underground and Obscured Object Imaging and Detection, Ed. N. Del Grande, I. Cindrich and P. Johnson, Orlando FL (1993).

15. Del Grande, N. K., P. F. Durbin and D. E. Perkins, "Dual-Band Infrared Imaging Applications: Locating Buried Minefields, Mapping Sea Ice and Inspecting Aging Aircraft", Proceedings: Quantitative Nondestructive Evaluation Conference San Diego, CA (1992).

16. Del Grande, N. K., K. W. Dolan, P. F. Durbin, M. R. Gorvad, B. T. Kornblum, D. E. Perkins, D. J. Schneberk and A. B. Shapiro, "Three-Dimensional Dynamic Thermal Imaging of Structural Flaws by Dual-band Infrared Computed Tomography" Proceedings of SPIE Conference 1942: Underground and Obscured Object Imaging and Detection, Ed. Nancy Del Grande, Ivan Cindrich and Peter Johnson, Orlando FL (1993).

17. Del Grande, N. K., K. W. Dolan, P. F. Durbin, M. R. Gorvad and A. B. Shapiro, "Dynamic thermal tomography for nondestructive inspection of aging aircraft" in Proceedings of SPIE Conference 2001: Nondestructive Inspection of Aging Aircraft. Ed. Michael Valley, Albert Kobayashi and Nancy Del Grande, San Diego CA (1993).

18. Del Grande, N. K., "Dual Band Infrared Imaging for Quantitative Corrosion Detection in Aging Aircraft", Proceedings of the Fall Meeting. American Society for Nondestructive Testing, Long Beach, CA, Nov. (1993).

19. Del Grande, N. K., "Method for Identifying Anomalous Terrestrial Heat Flows"; Patent No.4.005.289(1977).

20. LeSchack, L. A., and N. K. Del Grande, "A Dual-Wavelength Thermal Infrared Scanner As A Potential Airborne Geophysical Exploration Tool", Geophysics 41, 1318 (1976).

21. Grinzato, E. G., C. Bressan, P. G. Bison, A. Mazzoldi, P. Baggio, C. Bonacina, "Evaluation of moisture content in porous material by dynamic energy balance", in Proceedings of SPIE Conference 1682: Thermosense X1V Ed. Jan K. Eklund, Orlando FL p. 213 (1992).

22. Bison, P. G., C. Bressan, E. Grinzato, S. Marinetti, V. Vavilov, "Active thermal testing of moisture in bricks", in Proceedings of SPIE Conference 1933: Thermosense XV, Ed. Lee R. Allen, Orlando FL p. 207 (1993).

23. Delpech, Ph. M., D. M. Boscher, F. Lepoutre, A. A. Deom and D. L. Balageas, "Quantitative nondestructive evaluation of carbon-carbon composites by pulsed infrared thermography", in Review of Progress in Quantitative Nondestructive Evaluation. 12B. Ed. by Donald O. Thompson and Dale E. Chimenti, Plenum Press, New York and London, p. 1297 (1993).

24. Spicer, Jane W. Maclachlan, "Thermographic NDT", SPIE Short Course Notes. SC37. Thermosense '93, Orlando FL Section 5, p. 13, 1993. 


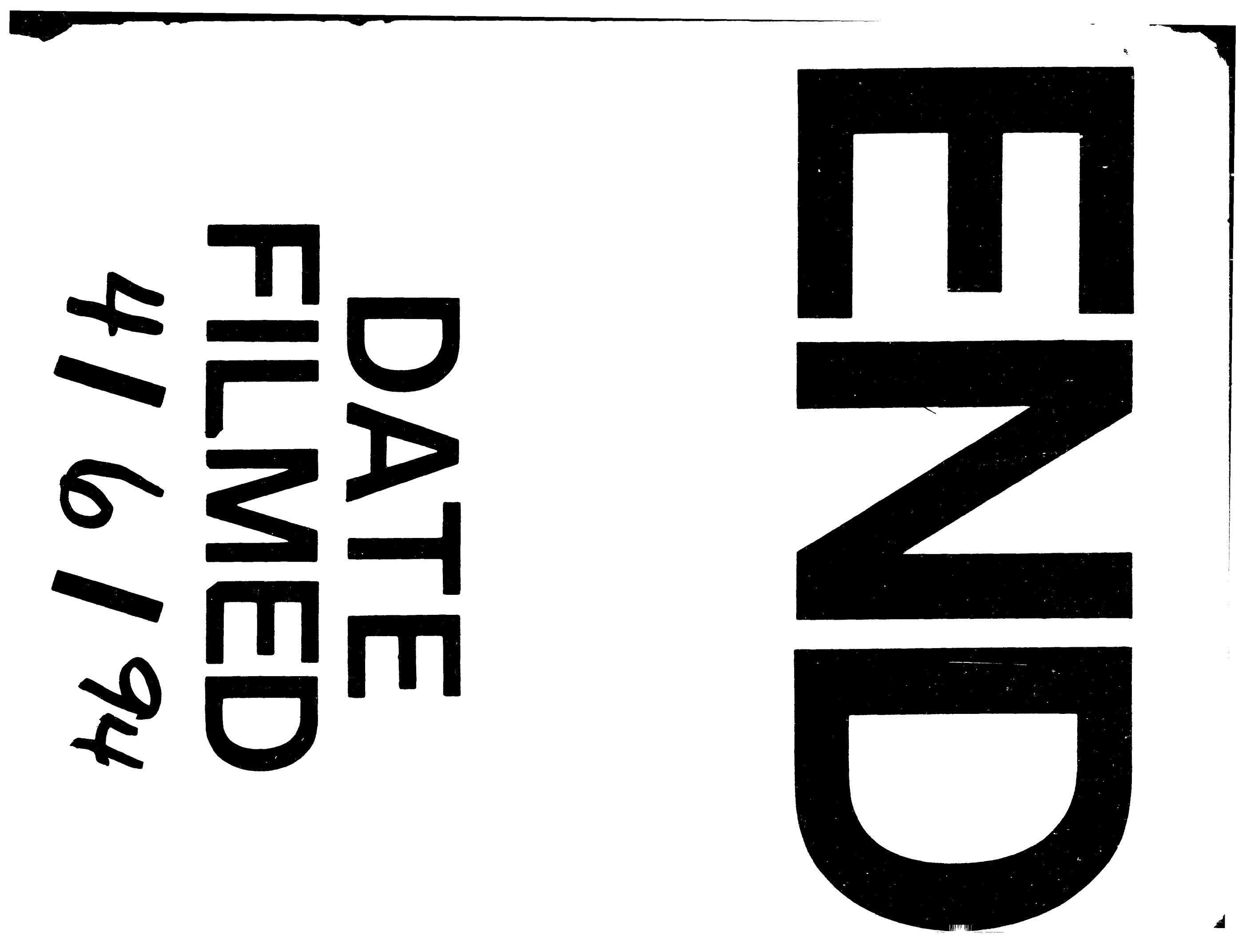


